First Peoples Child \& Family Review

A Journal on Innovation and Best Practices in Aboriginal Child Welfare Administration,

Research, Policy \& Practice

\title{
Domestic Sex Trafficking of Aboriginal Girls in Canada: Issues and Implications
}

\section{Anupriya Sethi}

Volume 3, Number 3, 2007

URI: https://id.erudit.org/iderudit/1069397ar

DOI: https://doi.org/10.7202/1069397ar

See table of contents

Publisher(s)

First Nations Child and Family Caring Society of Canada

ISSN

1708-489X (print)

2293-6610 (digital)

Explore this journal

Cite this article

Sethi, A. (2007). Domestic Sex Trafficking of Aboriginal Girls in Canada: Issues and Implications. First Peoples Child \& Family Review, 3(3), 57-71.

https://doi.org/10.7202/1069397ar

\section{Article abstract}

The current discourses on human trafficking in Canada do not take into account domestic trafficking, especially of Aboriginal girls. Notwithstanding the alarmingly high number of missing, murdered and sexually exploited Aboriginal girls, the issue continues to be portrayed more as a problem of prostitution than of sexual exploitation or domestic trafficking. The focus of this study is to examine the issues in sexual exploitation of Aboriginal girls, as identified by the grass root agencies, and to contextualize them within the trafficking framework with the purpose of distinguishing sexual exploitation from sex work. In doing so, the paper will outline root causes that make Aboriginal girls vulnerable to domestic trafficking as well as draw implications for policy analysis.
This document is protected by copyright law. Use of the services of Érudit (including reproduction) is subject to its terms and conditions, which can be viewed online.

https://apropos.erudit.org/en/users/policy-on-use/ 


\title{
Domestic Sex Trafficking of Aboriginal Girls in Canada: Issues and Implications
}

\author{
Anupriya Sethi
}

\section{INTRODUCTION}

\section{General trends}

Human trafficking has received growing attention in recent years, both in Canada and worldwide, especially in the wake of increased focus on nation States' security and tightening the borders (OxmanMartinez, Hanley, Gomez, 2005). The discourses on sex trafficking of women and girls in Canada continue to highlight international trafficking thus positioning Canada more as a transit and destination country than an origin country. Notwithstanding the fact that 500 Aboriginal ${ }^{1}$ girls and women (and maybe more) have gone missing over the past thirty years (Amnesty International, 2004), domestic trafficking has not received the attention it deserves. Instead of being contextualized in a trafficking framework, sexual exploitation of Aboriginal girls is portrayed and understood as a problem of prostitution or sex work.

Similarly, despite the wide-ranging and often complex problems facing Aboriginal peoples today, policies continue to be dominated by a limited range of issues like health, violence, poverty and the criminal justice system (Stout \& Kipling, 1998). This coupled with the tendency in policy decisions to analyze one issue at a time as against a holistic approach limits, if not excludes, the examination of linkages with the sexual exploitation of Aboriginal girls in Canada.

Questions or correspondence concerning this article may be addressed to:

anupriyasethi@yahoo.ca

\begin{abstract}
The current discourses on human trafficking in Canada do not take into account domestic trafficking, especially of Aboriginal girls. Notwithstanding the alarmingly high number of missing, murdered and sexually exploited Aboriginal girls, the issue continues to be portrayed more as a problem of prostitution than of sexual exploitation or domestic trafficking. The focus of this study is to examine the issues in sexual exploitation of Aboriginal girls, as identified by the grass root agencies, and to contextualize them within the trafficking framework with the purpose of distinguishing sexual exploitation from sex work. In doing so, the paper will outline root causes that make Aboriginal girls vulnerable to domestic trafficking as well as draw implications for policy analysis.
\end{abstract}

\section{Significance, Purpose and Limitations of Study}

The focus of this study is to identify key issues in domestic trafficking of Aboriginal girls, and outline implications for policy formulation and implementation at various levels of the Canadian government- federal, provincial and territorial, First Nations government as well as other agencies such as media, law enforcement officials, social welfare services, and justice system. The purpose is to highlight the issues, as identified by the grass root agencies working with trafficked girls, and to contextualize them within the trafficking framework in order to distinguish sexual exploitation from sex work. The study begins by outlining the definition of trafficking, which will form the basis of subsequent discussion and analysis in the paper. The next section examines the root causes that make Aboriginal girls vulnerable to sex trafficking, and the exploitation and manipulation they face in the trafficking process. 
Recommendations for policy research and analysis are discussed in the final section.

Although this paper brings forth some key issues in the domestic trafficking of Aboriginal girls today, it is a preliminary study restricted in its scope and application. The primary limitation of this research is that it is based on the feedback and input of NGOs working with trafficked girls in Canada and does not necessarily reflect the views of the trafficked girls themselves. This is because all interviews with the key informants of this research were done over the phone due to constraints of mobility and time, but for the exception of a roundtable held in Vancouver, BC. Hence, it was considered inappropriate, unethical and impractical to interview sexually exploited girls over the phone. Another limitation is that the paper makes reference to all Aboriginal girls rather than making a distinction between First Nations, Inuit and Métis girls whose issues and realities could be similar and yet different. The limited data available on domestic trafficking combined with the small sample size made it difficult to identify the issues specific to each Aboriginal community. Finally, due to its limited scope, the paper does not necessarily draw linkages between domestic and international trafficking.

Furthermore, it is essential to note that the study focuses primarily on the sexual exploitation of Aboriginal girls and not Aboriginal women. While some issues are common to both women and girls, there are significant differences regarding the concepts, policies and laws that are applicable to each group. Therefore, to maintain clarity and keeping in view the fact that Aboriginal women are being initiated into sex trafficking at an increasingly younger age (Assistant Deputy Ministers' Committee, 2001), the focus of this study is Aboriginal girls.

\section{Methodology}

Considering the limited information available on domestic trafficking of Aboriginal girls in Canada, the methodology adopted for this study was two fold. The first phase involved conducting interviews and discussions with key informants from NGOs, women's organizations and other community-based groups or individuals dealing with the issue of sexual exploitation in Canada ${ }^{2}$. A total of 18 key informants participated in the study. Five key informants were interviewed over the phone from four regionsQuebec (1), Prairies \& NW Territories (2), Ontario
(1), Atlantic (1). In BC, a one-day roundtable was organized in Vancouver on 7th July 2006, which was attended by thirteen representatives from different community groups.

While majority of the key informants were front line workers, some were researchers and program coordinators, and a couple of them were the manager or director of the organizations providing services to sexually exploited women. Few key informants, now working as service providers, identified themselves as trafficked into sex trade in the past. The mandate of the key informants' organizations ranged from providing drop-in services to outreach, counseling, research, advocacy and/or a combination of these services. The interviews with the key informants were semi-structured and lasted for about 45 minutes to an hour.

The questions and discussions with the key informants covered three main areas- First, participants were asked about the mandate and clientele of their organization, and their experiences of working with sexually exploited girls. Second, informants outlined the root causes of sex trafficking, the methods traffickers use to maintain control and dominance over the girls, and the role of racism in the sexual exploitation of Aboriginal girls. Finally, the informants were asked to comment on the existing policies and programs to address domestic trafficking of Aboriginal girls and make suggestions, both at the policy and grass root level, to address the issue.

The second phase of the project involved analyzing the information gathered from the discussions and consultations with key informants, and substantiating it with published research in the form of journal articles, reports, government documents and other related materials.

\section{OVERVIEW}

\section{Definition of Trafficking}

This paper draws upon the trafficking definition of the United Nations Protocol to Prevent, Suppress, and Punish Trafficking in Persons, especially Women and Children, Supplementing the United Nations Convention Against Transnational Organized Crime.

"Trafficking in Persons shall mean the recruitment, transportation, transfer, harboring, or receipt of persons, by means of threat or use of force or other 
forms of coercion, of abduction or fraud, of deception, of the abuse of power of a position of vulnerability or of the giving or receiving of payment or benefits to achieve the consent of a person having control over other persons, for the purpose of exploitation. Exploitation shall include, at a minimum, the exploitation of the prostitution of others or other forms of sexual exploitation, forced labor or services, slavery or practices similar to slavery, servitude or the removal of organs" (United Nations Crime and Justice Information Network, 2000).

As outlined in this definition, trafficking comprises use of threat, force, deception, fraud, abduction, use of authority and giving payment to achieve consent for the purpose of exploitation, including sexual exploitation. The element of 'consent' in the trafficking definition is usually misunderstood thus conflating sexual exploitation with sex work. It is often argued that a person who consents to engage in prostitution cannot be considered trafficked thereby suggesting that only coercion or force should form an integral part of the trafficking definition. However, it is essential to recognize that consent does not necessarily suggest an informed choice. As one key informant remarked, 'it is rare that Aboriginal girls or women of color experience sex work. They are often trafficked for power and control, and coerced into prostitution for their survival needs'. Therefore, this paper would consider all those circumstances, which are elaborated in root causes, that lead to the sexual exploitation of girls as part of trafficking.

\section{Scope of Domestic Trafficking}

There is no national level data that tracks the transient Aboriginal population and their trafficking in sex trade. Lack of focus and/or clear understanding of domestic trafficking since sexual exploitation is often conflated with sex work, underground nature of the crime, and mobility of the trafficked persons across various cities, often make it difficult to assess the actual numbers. Moreover, majority of the cases of trafficking go unreported as girls are scared to take action against their traffickers ${ }^{3}$, resulting in the data on trafficked persons being partial, varied and debatable.

In the absence of actual figures on domestic sex trafficking in Canada, a look at the number of Aboriginal girls in prostitution can help throw some light on the extent of the issue. First Nations girls are overrepresented in prostitution with an especially high number of youth ranging from 14\% - 60\% across various regions in Canada (Assistant Deputy Ministers' Committee, 2001). National data in Canada reveals that $75 \%$ of Aboriginal girls under the age of 18 have experienced sexual abuse, $50 \%$ are under 14 , and almost $25 \%$ are younger than 7 years of age (Correctional Service of Canada, cited in McIvor and Nahanee, 1998). In Vancouver alone, $60 \%$ of sexually exploited youth are Aboriginal (Urban Native Youth Association, 2002). One key informant reported that children as young as 9 are sexually exploited in Saskatoon and the average age of being forced into prostitution is 11 or 12 .

Although the limited data available on sexual exploitation focuses primarily on urban centers like Vancouver, Toronto, and Montreal, it does not imply that the issue is less chronic in smaller cities and rural Aboriginal communities. Only that it is not widely known or acknowledged (Blackstock, Clarke, Cullen, D'Hondt, and Formsma, 2004).

\section{Pattern of Domestic Trafficking}

Domestic sex trafficking of Aboriginal girls in Canada has various forms. It can be familial-based i.e. family members forcing other members to take part in sex trade. For instance, there are communities in the North wherein First Nations girls are sexually exploited and initiated into prostitution by their male and female relatives- brother, father, grandfather or an uncle (Lynne, 1998). Many key informants identified familial-based sex trafficking as povertydriven and intergenerational or cyclical resulting from the residual impact of colonization and residential schools. Another type of sex trafficking is organized (gang related) and sophisticated in the form of escort services, massage parlors or dancers. One key informant referred to the hidden forms of domestic trafficking such as the existence of "trick pads" 4 in some parts of Canada.

Additionally, key informants pointed out a characteristic intrinsic to the trafficking process- the movement of trafficked Aboriginal girls that follows a pattern of city triangles across different provinces in Canada. For instance, in Saskatoon, which is in close proximity to Edmonton and Calgary, girls are moved in triangles such as Saskatoon- Edmonton- CalgarySaskatoon and Saskatoon- Regina- WinnipegSaskatoon. These triangles, often inter -connected, 
are spread across Canada. For example, once girls are trafficked into Calgary, the triangle is CalgaryEdmonton-Vancouver. Although several factors contribute to the movement of girls, an emerging trend that a key informant pointed out, is the increased trafficking of girls due to the flourishing oil rigors and mining businesses in Alberta. Significant number of men travel back and forth from Saskatchewan to northern Saskatchewan or Alberta for short periods of time to work in oil rigs or at uranium mines. In keeping with their movement, girls are increasingly being moved around and sexually exploited.

\section{RECRUITMENT METHODS}

Coercion and deception are the underlying elements in the various methods that traffickers use to force Aboriginal girls in sex trafficking. Consultations with key informants of this research project revealed some of the ways of the recruitment of girls.

Airports: A couple of key informants identified airports as the point of recruitment in big cities like Montreal, which are witnessing a growing movement of Aboriginal girls, especially Inuit, from Northern communities. Traffickers often know someone in the community who informs them about the plans of the girls moving to the city. Upon their arrival at the airport, traffickers allure the girls under the pretext of providing a place to stay or access to resources. In the words of a key informant working as an Aboriginal outreach worker, 'Girls tend to believe in the promises of the traffickers as they are young, naïve and vulnerable in a new and big city. They are unsuspecting of the motives of the traffickers, since they belong to communities that have a culture of welcoming strangers'.

Schools: In cities like Winnipeg, Vancouver and others with high concentrations of Aboriginal peoples, traffickers are increasingly targeting schools as recruiting grounds. Traffickers entice Aboriginal girls, as young as in grade six or seven, on school playgrounds or on their way to school by promising them gifts, a good life style or getting them addicted to drugs (West, 2005). These girls are too young and vulnerable to understand or take action against sexual exploitation.

Bars: Several key informants discussed 'bars' as a fertile recruiting ground successfully targeted by traffickers. Young Aboriginal girls who move from reserves to big cities might go to bars to "bridge the isolation" and connect with other Aboriginal peoples, especially since community centres in many cities close early in the day. Traffickers frequent these places to befriend girls, by buying them a drink or offering to help connect with other Native peoples, and later sexually exploit them.

Boyfriends: In many cases, traffickers pose as boyfriends and seduce young girls by buying them expensive gifts and/or emotionally manipulating them. Hence, it is not uncommon for sexually exploited girls to refer to the traffickers as their boyfriends. Due to their emotional and economic dependence on the traffickers, many girls refuse to identify themselves as sexually exploited (Thrasher, 2005).

Girls as recruiters: In yet another method, trafficked girls, as young as 11, are forced to recruit other girls (Urban Native Youth Association, 2002). When young girls approach their counterparts with dreams of a better lifestyle, it is real and convincing. Girls working as recruiters, in most cases, have no choice but to agree to the wishes of the trafficker due to fear or, in some cases, to meet their survival needs. It often results in a hierarchal set up wherein recruiters take the share of the earnings of the girls they have recruited. As recruiters move up in the hierarchal chain, they aim to get rid of the street work.

Dancers: Aboriginal girls, recruited as dancers at a young age, are frequently moved across provinces for their dance shows. Over a period of time, they lose ties with their home and community thus becoming isolated and vulnerable. When these girls grow old, appear less attractive and are forced out of dancing, they are sexually exploited for their survival needs.

Internet: Traffickers are increasingly using internet as a means to entice young Aboriginal girls, especially in rural communities (Thrasher, 2005), with the charm of a big city or false promises of a good job. Once these girls are in the cities, away from their family and friends, they are trafficked into the sex trade.

Hitchhiking: First Nations intergenerational poverty, lack of recreation and social activities for youth on-reserve, and inadequate public transportation facilities force young girls to hitch hike thus making them vulnerable to sexual exploitation. The Yellow Head Highway in BC, also known as the Highway of Tears, along which several Aboriginal girls have 
gone missing or found murdered (Wilson, 2004), is a glaring example.

\section{ROOT CAUSES}

Key informants of this study identified the root causes that affect the safety and well-being of Aboriginal girls and put them at risk of sex trafficking. Although discussed under separate headings for the sake of simplicity and clarity, these causes are interrelated thus forming a vicious circle. It is important to note that while factors such as poverty, violence, and racism surface in various discussions in existing literature and policy decisions on Aboriginal peoples, their linkages with sexual exploitation have not been fully explored (Blackstock, Clarke, Cullen, D'Hondt, and Formsma, 2004).

\section{Legacy of Colonization and Residential schools}

Majority of the key respondents referred to the history of colonization as a fundamental factor behind the sexual exploitation of Aboriginal girls. Various aspects of colonization such as capitalism, church and the military has affected family units, language, culture and identity, economic status and parenting abilities of Aboriginal peoples (Lynne, 1998). The destruction of the social structures and family support system has rendered some communities dysfunctional thus leading to increased rates of violence, sexual abuse, substance abuse and suicide rates (Bennett \& Shangreaux, 2005).

According to one key informant, sex has traditionally been considered sacred in Aboriginal culture - A gift from the creator and a way to communicate. As a result of colonization, sexual abuse was introduced to Aboriginal communities, now living with the "historic imagery of Aboriginal girls being sexually available". Due to the intergenerational effects of residential schools, men and women have not learnt the meaning of healthy sexuality and parenting resulting in many residential school survivors sexually exploiting their own children (Assistant Deputy Ministers' Committee, 2001). Girls suffering perpetual violence and abuse have no choice but to leave their communities in search for a safer place. This coupled with culturally inappropriate welfare practices and lack of adequate support systems further expose them to the risk of sex trafficking.

\section{Lack of Awareness, Acknowledgment and Understanding of Sexual Exploitation}

Sections of the Canadian society such as Aboriginal communities (Thrasher, 2005), law enforcement officials, media, policy-makers, and legal system are unwilling to acknowledge domestic trafficking, especially of Aboriginal girls.

According to key informants, several factors prevent Aboriginal communities from acknowledging the sexual exploitation of their girls. These include poverty, limited resources, lack of education and understanding of the exchange of sexual favors for goods and resources as sexual exploitation and the fear of outside involvement resulting from ineffective past interventions. As one key informant remarked, 'our people have been researched to death but nothing has been done'.

Aboriginal girls in rural communities might be reluctant to talk about sexual exploitation, as sometimes they are battling with their own physical and mental health problems such as HIV/AIDS, sexually transmitted infections, depression and post traumatic stress disorder. Inadequate resources and the taboo associated with such diseases limits their capacity to advocate for ending sexual exploitation.

Limited initiative and willingness on the part of law enforcement authorities to actively deal with sex trafficking aggravates the reluctance in Aboriginal communities. One key informant mentioned a case wherein a law enforcement official, while speaking on the issue of sexual exploitation, expressed hesitation to specifically talk in the context of Aboriginal girls stating that 'they (police) do not work in the First Nations communities'. In cases, where officials do take a proactive approach to undertake research or document cases, they often lack the culturally relevant approaches or tools to address it adequately.

The lack of acknowledgement of sexual exploitation of Aboriginal girls acts a hindrance to initiating and implementing measures for addressing it. Thus, sexual exploitation continues to be viewed as or conflated with sex work. Aboriginal peoples are stereotyped as 'willing' to take up sex work and a great deal of ignorance surrounds Aboriginal culture and their living conditions. 


\section{Violence}

A significant consequence of colonist government policies is the violence plaguing Aboriginal communities. Loss of cultural identity coupled with social and economic marginalization fuels violence and sexual assault (Mann, 2005). As pointed in the Aboriginal Justice Enquiry in Manitoba, violence in Aboriginal communities has reached epidemic proportions (Hamilton \& Sinclair, 1991). While there are complexities in defining and contextualizing violence in Indigenous communities, suffice it to say that as a result of oppression and colonization "violence has invaded whole communities and cannot be considered a problem of a particular group or an individual household" (Jacobs, 2002 p.3). Increased family breakdown due to violence is resulting in an ever- increasing number of Aboriginal children in the welfare system. They experience culture loss and disassociation, and become extremely susceptible to sexual exploitation as a means to meet their emotional and practical needs.

The cycle of violence, that Aboriginal girls face, begins from their communities and continues into the trafficking process. Traffickers impose various forms of violence-physical, emotional, economic and sexual to initiate girls into sex trafficking and maintain control over them. Girls are forced to go with johns, not use condoms, and live in poor and unhygienic conditions. Traffickers often keep the earnings and the identification documents of girls to minimize their chances of escape, as in the absence of identification, girls have negligible or limited access to resources such as welfare services or addiction treatments.

\section{Poverty}

As Raven Bowen (2006) found in her study on domestic trafficking, poverty is a major cause of sexual exploitation. Girls are forced to move in search of survival opportunities and in the process suffer the kind of exploitation and isolation that is similar to that of international trafficking or organized crime. Poverty in Aboriginal families have reached an all time high, with $52.1 \%$ of all Aboriginal children living in extreme poverty (Ontario Federation of Indian Friendship Centres, 2000). In urban Winnipeg, Regina and Saskatoon, 80 to $90 \%$ of single Aboriginal mothers were living below the poverty level (Royal Commission on Aboriginal Peoples (RCAP), 1996).
One of the main reasons for poverty among Aboriginal girls is the limited opportunities for employment and education. On-reserve unemployment is three times the national average and, in some Aboriginal communities, about $90 \%$ of the population is unemployed (McKenzie \& Morrissette, 2003). High rates of unemployment coupled with limited welfare services leads to poor health, violence, cultural disintegration and increased poverty rates among Aboriginals (Bennett \& Shangreaux, 2005). High level of poverty in a patriarchal society is directly related to high rate of sexual exploitation (Farley \& Lynne, 2005).

Closely related to poverty is homelessness, which is another significant risk factor in sexual exploitation (Farley \& Lynne, 2005). Although the population of Aboriginal peoples is growing at a rapid rate, their housing needs remain unmet. Lack of affordable housing is evident from the fact that $84 \%$ of Aboriginal households on-reserve do not have sufficient income to cover the cost of suitable and adequate housing (RCAP, 1996). In the face of extreme poverty and consequently the absence of safe and affordable housing, girls become vulnerable to sexual exploitation to meet their basic needs of food, clothing and shelter.

\section{Isolation and Need for a Sense of Belonging}

Girls experience isolation in rural Aboriginal communities due to various reasons- boredom, dysfunctional families, limited education and employment opportunities, and taboo due to HIV/ AIDS, Hepatitis C and other sexually transmitted infections. Traffickers lure young girls by glamorizing life in a big city and presenting it as a way out of their communities.

The movement from reserve to big cities can be an overwhelming experience for many young girls brought up in a culture of strong family and community ties. In cities, they suffer isolation, racism and consequently low self-esteem. During the course of time, they lose contact with their communities and experience culture loss (Save the Children Canada, 2000). Many girls go to bars to overcome their isolation and end up being recruited by traffickers. Limited knowledge and availability of resources to Aboriginal peoples off-reserve further puts the young girls at risk. 
Once forced into sex trade, Aboriginal girls continue to suffer sexual exploitation and turn "to street communities, drugs, pimps and dealers to develop personal identities and an enduring sense of place and belonging" (Downe, 2003, p.47). There is a spirit of camaraderie and unity among trafficked girls, as they share the same stories and a common history. Driven by the desperate need for trust and acceptance, many Aboriginal girls find love in their traffickers who they often refer to as their boyfriends. 'It is amazing what girls can do to feel that they belong', one key informant remarked. In such a scenario, although girls consent to being sexually exploited, they do it as they have no choice or means to help them in their loneliness, marginalization and lack of support system. Hence, it is essential to recognize isolation and social exclusion as a root cause of sex trafficking, instead of viewing it as a part of voluntary sex work.

\section{Racism}

The systemic racism that Aboriginal girls face from different sections of the Canadian society- media, justice, police, law-makers, service providers and the Canadian society at large, emerged as a key factor in discussions with almost all the key informants. In addition to the inadequate representation of Aboriginal peoples in the media, the ignorance and stereotypes associated with their culture and identity marginalizes them, especially youth. Aboriginal girls are perceived as 'easily available' due to the discriminatory and sexist polices, and their unequal status in the Canadian society (Mann, 2005; Olsen 2005). A study (Gorkoff \& Runner, 2003) involving 45 interviews with sexually exploited girls revealed that Aboriginal girls are at risk not just because they are female, poor and homeless but also because they suffer racism and exclusion. Thus, the sexual exploitation of Aboriginal girls is yet another form of racial discrimination.

While stressing on the lack of concern or interest towards Aboriginal girls in sex trafficking, one of the key informants mentioned a profound example wherein a large number of people attended a presentation that a local faith based agency had organized to highlight the international trafficking of girls from Ukraine to Canada. However, the turn out of people is significantly low when such initiatives are organized for addressing trafficking of Aboriginal girls in their own city. 'People are willing to speak abut trafficking in terms of World soccer and Asian gangs but disinterested to talk about the sexual exploitation of young Aboriginal children in their own backyard', remarked the key informant. This indifference and discrimination towards the plight of Aboriginal girls reflects a NIMBY (Not-In-My-Backyard) syndrome, also known as NIMBY-ism. The NIMBY syndrome is often widespread and deep-seated, and involves intentional exclusion and inhibition of growth (Kean, 1991). In 1996 trial of John Martin Crawford, a serial killer convicted of killing three Aboriginal girls, Warren Goulding, one of the journalists covering the trial said, "I don't get the sense the general public cares much about missing or murdered Aboriginal girls. It's all part of this indifference to the lives of Aboriginal people. They don't seem to matter as much as the white people" (Amnesty International, 2004, p.24).

\section{Substance Use}

Drug addiction "sucks Aboriginal girls in and keeps them there". Traffickers lure young girls into taking drugs and then sexually exploit them. In many cases, Aboriginal girls with no prior history of substance use, take drugs to numb the pain of shame and humiliation they experience as a result of being sexually exploited. A study by Ontario Native Women's Association (1989) found that eight out of ten Aboriginal girls have suffered some form of abuse- physical, sexual, psychological or ritualin their communities and that these factors were associated with high rates of alcohol and drug use in these communities. Over time, the substance use develops into a chemical dependency ${ }^{5}$, which forces girls to engage in prostitution in order to support their addiction. One key informant quoted a trafficked girl, "I have two choices - To do drugs or to die".

\section{Role of gangs}

Gangs are playing an increasing role in the sexual exploitation of Aboriginal girls. Some of the Aboriginal-based street gangs include the Manitoba Warriors, the Native Syndicate and the Indian Posse (Turenne, 2006). One key informant observed that a number of Asian and Somali gangs have been able to recruit Aboriginal girls and traffic them into the sex trade. Recruitment of gang members takes place not only in urban centres but also on-reserves and small rural communities (Criminal Intelligence Service 
Canada, 2004). The average age of a female gang member ranges from 11-30 years with the majority between 14-25 years. The fastest growing street gang population consists of young children under 16 years old (Nimmo, 2001).

The reasons for young girls falling a prey to gang recruitments vary- poverty; physical, emotional and sexual abuse in their families and communities; sense of power, recognition and protection from street life; and most importantly, the need for belongingness and acceptance (Fontaine, 2006). Many young girls are attracted to gangs because they have suffered loss of cultural ties and find an alternative 'family' in the gangs (RCAP, 1996; Native Women's Association of Canada (NWAC ), 2007a).

Most gangs thrive in drug trafficking; however some engage in sex trafficking as well. The gang culture follows a hierarchal framework in which there are powerful few at the top followed by the various levels of workers underneath (Nimmo, 2001). Accordingly, gang members have different status and roles. Prostitution is considered as the lowest activity in the gang and young girls, who are at the bottom of the hierarchy, are forced into prostitution to earn money for the gangs (Nimmo, 2001; Fontaine, 2005). These girls are also exploited to recruit other young girls in order to move up in the hierarchy and away from the street work.

\section{Gaps in service provision}

Key informants pointed towards the existence of a cycle of power, control and systemic oppression in the way services are delivered to sexually exploited girls. The narrow mandate and rigid functioning of certain agencies limits the scope and extent of services available to girls. For instance, trafficked girls usually work in the night and sleep during the day but most shelters do not accommodate this pattern (Canadian Housing and Renewal Association, 2002). Similarly, the long waiting period in service provision combined with the lack of consistent long-term funding act as deterrents for girls wanting to escape sexual exploitation. This is particularly true for the treatment of alcohol and drug addiction, which is often a difficult service to access. Healing and transition to a normal life is usually a lengthy process (Assistant Deputy Ministers' Committee, 2001), especially if a woman has been abused and exploited at a young age or for a long period. However, limited and short- term funding focused on instant results fails to take into consideration the period required for healing and is often not enough to help trafficked girls make the transition to a healthy life. As one key informant effectively summed up - 'Drugs are more easily available than counseling or other support services'.

Culturally relevant services managed by Aboriginal peoples are minimal and even more limited are the services specifically for sexually exploited Aboriginal girls (Canadian Housing and Renewal Association, 2002). For instance, many key informants pointed out the scarcity of female-only residential treatment centres and the unwillingness and/or inability of these centres to address sexual exploitation issues. Treatment of addictions without addressing sex trafficking has limited effectiveness. Moreover, placing sexually exploited girls with other groups such as battered women may lead to bias and discrimination due to issues of class, and is usually not helpful as the problems and interventions for these groups are different from each other. Co-ed treatment centers can be unsafe for girls as older men in these centres may sexually exploit young girls (Canadian Housing and Renewal Association, 2002).

The contradictory welfare policies along with the lack of suitable alternatives for income also pose a barrier to girls wanting to exit domestic trafficking. A key informant working as an Aboriginal outreach worker discussed the problem of girls losing their housing when admitted to residential treatment centres, as welfare stops paying for it. Considering that finding a safe and affordable housing is a challenging task, such policies may uproot girls and make them further vulnerable to trafficking. Similarly, in the absence of apprenticeship programs, the employment opportunities for Aboriginal girls are limited especially since they have little or no education due to their trafficking at a young age. The gaps and barriers in service provision frustrate Aboriginal girls who often find it difficult to sustain their fight against sexual exploitation, which seems to be "the only thing normal and working".

\section{Discriminatory Policies and Legislations}

Several policies and legislations continue to marginalize Aboriginal peoples, especially girls. For instance, in the absence of clear policies around matrimonial property rights, Aboriginal girls are forced to leave their homes when marriages break- 
up. The shortage of alternative housing services onreserves and in rural communities forces girls to move to cities where they live in poverty thus becoming highly susceptible to sex trafficking. Similarly, Section 67 and Bill C-31 of the Canadian Human Rights Act discriminate against Aboriginal girls and their descendents, and negatively impact their rights and chances of a respectful life (NWAC, 2006).

Section 67 of the Canadian Human Rights Act provides that nothing in the Act affects any provision of the Indian Act, thus prohibiting Aboriginal peoples from lodging a complaint against the federal or the Native government. Such a provision perpetuates the oppression that status Indian girls face in their communities and leaves them without any protection that is available to other Canadian girls (Native Women's Association of Canada, 2007b). Despite amendments to the Indian Act, Section 6 in Bill C-31 translates into a loss of status after two consecutive generations of girls have married with non-registered partners and it is anticipated that by 2060 , there will be no Aboriginal people with Indian Status (Mann, 2005). The benefits that Aboriginal girls are entitled to under registered status are of great importance since they remain the primary care givers in the family. Some of these benefits include access to Indian and Northern Affairs Canada's programs, nationallevel services, non-insured health payment and tax benefits in addition to non- tangible benefits such as identification with their culture and community (Mann, 2005). The denial of these benefits may further isolate Aboriginal girls making them an easy target for traffickers.

\section{POLICY RECOMMENDATIONS}

Based on the analysis of the root causes that make Aboriginal girls vulnerable to sex trafficking and the factors that contribute to their ongoing exploitation in sex trade, the key informants of this study made the following policy recommendations:

\section{Acknowledgment and Recognition}

Sexual Exploitation - A trafficking and human rights issue:

The first step in addressing domestic trafficking of Aboriginal girls is to acknowledge the seriousness of the problem. Countries like Canada are increasingly under pressure to tighten their borders and undertake measures on the prosecution aspect of human trafficking, especially in the wake of US Trafficking in Persons (TIP) report. The over emphasis on criminalizing the movement of people across borders has shifted the focus away from trafficking as a human rights issue. Moreover, the discourses in transnational trafficking in Canada do not include domestic trafficking of Aboriginal girls within and across provinces. It is erroneous and unjust to consider domestic trafficking as less serious than transnational trafficking because the issues of control, isolation and exploitation that girls face at the hands of traffickers are severe irrespective of whether it is cross-cultural or cross-border (Bowen, 2006).

\section{Honor Indigenous Knowledge:}

There is a serious need to recognize and honor Indigenous knowledge (Stout \& Kipling, 1998) by engaging "Aboriginal people as knowledge-keepers". Awareness and education programs are effective when implemented through participatory, interactive and inclusive processes that acknowledge the lived experiences of Indigenous peoples. Significant amount of research has been done on Aboriginal communities. While continuing further research in unexplored areas, the critical knowledge that already exists needs to be utilized and acted upon. The already identified gaps such as homelessness, poverty and unemployment demand action, as against further research and deliberations.

\section{Recognize Diversity among Aboriginal Peoples:}

Although larger systemic problems like poverty and impact of colonization are common to several Aboriginal communities, there are issues that are typical of each community. As pointed out by a key informant, 'saying someone is an Aboriginal is like saying someone is a European meaning that there are many groups, territories, languages etc of Aboriginal peoples'. Policy making should take into account this diversity, as there is no one pan-Aboriginal identity. Formulating and implementing a blanket policy meant to address the issues of all Aboriginal communities has limited effectiveness and sometimes perpetuates the already existing problems in different communities. 


\section{Collaboration}

\section{Establish a national level strategy for domes- tic trafficking:}

Due to the lack of understanding or acknowledgment of domestic trafficking, there is no national level strategy to address, both the immediate causes and the larger systematic issues, which lead to the sexual exploitation of Aboriginal girls. Key informants expressed frustration at the disconnect that exists among the various levels of the government and other agencies like law enforcement, justice, health care and child welfare. Considering that the issues identified in domestic trafficking fall under the mandate of various agencies, standardized protocols and guidelines are essential to bring together initiatives of different stakeholders. A uniform approach shall help in sharing information and ideas, increasing awareness about domestic trafficking, and enabling different agencies to work towards common goals.

\section{Bridge the Policy-Practice Gap:}

Many participants pointed out the existing policy-practice disconnect reflected in the policy decisions. Although both the grass root agencies and policy makers are experts in their respective areas, the communication gap between them is rather unproductive. A limited, if not negligible, understanding of the other side often creates and widens the gap between what is required and what ends up being delivered thus leading to quick fix solutions rather than addressing the fundamental problems.

Input from communities, women's groups and grass root agencies in the policy-making processes can help ensure an informed decision-making. Furthermore, it is crucial to engage in a dialogue with the trafficked Aboriginal girls regarding various social policy issues that affect them since their input is based on lived experiences. At the same time, it is important to ensure that these girls do not end up being a poster child. The story of one girl should not be regarded as a blanket experience of all sexually exploited girls, each with their own struggles and disadvantages. There is a wealth of knowledge and community experience at the grass root level, which should be validated and fed into the social policies.

\section{Alliance between Aboriginals and Non-Aboriginals:}

The success of non-Aboriginals in forming productive alliances with Aboriginals has been limited. A key informant observed that at one extreme is the lack of concern or a hands-off approach towards Aboriginal issues and on the other extreme is the fear of recolonizing Aboriginal peoples. The informant emphasized that the guarded approach on the part of non-Aboriginals is equally unhelpful, as it further isolates Aboriginal girls who end up fighting for their rights in isolation. Non-Aboriginals will have to learn to be good allies by supporting and collaborating with Aboriginals populations in a way that gives Aboriginal girls the power and right to determine what is best for them.

\section{Funding and Resources}

\section{Preventive rather than a Reactionary Approach:}

One key informant remarked that traditionally Aboriginal peoples view life as a cycle of seven generations. The wisdom from the past three generations is used to guide the present, which is the fourth generation, and lay the foundation for the future three generations. The understanding of this vision is not reflected in social policies today, which focus on immediate and reactionary measures instead of combining it with long term prevention strategies.

Funding and services should be directed towards prevention programs like educating and mobilizing young girls in Aboriginal communities, raising awareness regarding the dangers of sex trafficking, and increasing collaboration between urban Aboriginals and communities on-reserve so that girls do not lose touch with their culture and homes. In addition to focusing on young girls vulnerable to sex trafficking, prevention strategies should focus on girls who have exited sexual exploitation to prevent them from being retrafficked ${ }^{6}$. Funding should be granted for longer periods, as prevention work usually involves implementing a long-term strategy, which does not necessarily deliver quick results measurable in numbers. 


\section{Culturally Relevant Services:}

Aboriginal girls should have access to culturally relevant services that move beyond crisis intervention and are long enough to help them make a successful transition to a safe and healthy life. Key areas in service provision should include culture specific safe transitional housing for sexually exploited girls and their children similar to the program "Honouring the Spirit of Our Little Sisters" created by Ma Mawi Wi Chi Itata Centre in Winnipeg (see endnote no. 6), establishment of healing centres and shelters specifically to meet the needs of trafficked girls, and adequate child welfare managed by Aboriginal organizations. The existing welfare services should be made more accessible. For instance, increased access to programs like income security, flexible curfew times in shelters, follow-up support, and reduced wait times in treatment centres. Similarly, harm reduction should be recognized as a useful measure for the health and safety of sexually exploited girls. Services like needles, food, condoms, and education regarding HIV/AIDS and other sexually transmitted diseases should be readily available.

\section{Capacity Building of NGOs:}

Funding arrangements with NGOs should be flexible, adequate and long-term, especially for macro issues like domestic trafficking of girls. Key informants mentioned situations wherein agencies have to modify and, in some cases, reframe their mandates to fit the funding requirements. The excessive focus on the outcome of the funded initiatives affects the kind and extent of services that NGOs are able to offer to sexually exploited girls. The evaluation guidelines often make it difficult for NGOs working with vulnerable groups to demonstrate and quantify the work done at the ground level. Similarly, inconsistency in grants leads to NGOs devoting considerable time, energy and resources in arranging funds for their projects. The tight funding also leads to a high rate of employee turnover, as wages are limited and people are hired on a contract basis. A high turnover affects the efficiency of the NGOs' projects, which require building longterm partnerships with stakeholders.

Additionally, more resources and opportunities are needed to enhance communication and collaboration among different NGOs in order to enable them to coordinate their efforts against domestic trafficking - an issue which cuts across regions, instead of being confined to a specific area. The competitiveness for funding often leads to organizations working against each other rather than working with each other. Considering that a strong united voice is paramount to advocating for a social policy change, the funding arrangements should recognize the power dynamics and ensure that the role of NGOs as advocates for social justice remains unaffected.

\section{Capacity Building in Aboriginal Communities:}

Resources are needed for Aboriginal communities to support them in dealing with their challenges and problems. Aboriginal women are rather alone in their work against sexual exploitation of girls, especially on-reserves, where they face resistance from various sections like chiefs and counsels who refuse to admit that the problem has reached epidemic proportions (Save the Children Canada, 2000). Girls in Aboriginal communities should be mobilized and encouraged to take up the leadership role and teach their future generations to value both men and women.

Elders have a wealth of experience which they can share with youth to guide them through their curiosities, questions and dilemmas. Aboriginal youth should be provided an environment that facilitates an open dialogue with both their peers and elders. Similarly, there is a need for better role-models for young Aboriginal girls. A key informant spoke of a case wherein an Aboriginal girl, who had grown up in a city, came to live on-reserve. Just by being confident in her approach towards men, she subtly taught other Aboriginal youth the meaning of self-pride.

Schools and community service providers should be proactively engaged to decrease the drop-out rates of young children. Measures such as family support, counseling, homework clubs and culturally appropriate classes need to be in place to support children and keep them in the education system thus reducing their vulnerability to trafficking (Urban Native Youth Association, 2002). Resources should also be directed towards transportation, recreation facilities, awareness campaigns and apprenticeship programs in Aboriginal communities. 


\section{Legislative Reforms}

Matrimonial Property Law needs to be reviewed, in consultation and partnership with Aboriginal peoples, to ensure that Aboriginal girls living on-reserve have equal property rights as those living off-reserve. Policy and legislative changes are also required in Bill C-31 to remove the residual gender discrimination against Aboriginal girls and their descendants, and rectify the loss of status under the Indian Act (NWAC, 2006). Similarly, Section 67 of the Canadian Human Rights Act should be repealed and a parallel human rights system be established in consultation with Aboriginal representatives to ensure that Aboriginal girls have access to remedies for violations of their economic, social and cultural rights (NWAC, 2006).

\section{CONCLUSION}

Key informants of this study identified significant issues and implications in the domestic sex trafficking of Aboriginal girls in Canada. However, the root causes and recommendations highlighted in this paper need further examination and analysis to better inform the future initiatives in domestic trafficking in Canada. As a starting point, it is of utmost importance to determine the actual number of girls that are domestically trafficked in Canada including smaller cities and rural areas. Further research should also include other groups such as immigrant girls, visible minorities, Aboriginal boys or two-spirited youth. Although many root causes and recommendations in this report could be generalized to other groups as well, there are subtle differences in each group which need to be explored for a thorough analysis. Additionally, there needs to be focus on addressing the role of men in Aboriginal communities. National level initiatives catering specifically to the abuse and trauma that men have suffered as a result of colonization are limited. Domestic trafficking of girls will continue to be a self perpetuating phenomenon and the efforts to heal girls might not yield the desired results so long as the role of their abusers remains unaddressed.

As observed in the Aboriginal Justice Enquiry of Manitoba, "Aboriginal women and their children suffer tremendously as victims in contemporary Canadian society. They are the victims of racism, of sexism and of unconscionable levels of domestic violence" (Hamilton \& Sinclair, 1991). Instead of conveniently labeling domestic trafficking of Aboriginal girls as 'sex work', the holistic approach to dealing with it should begin by an acknowledgement of the problem from the various sections of the Canadian society. As recommended in the Article 4 of the Convention on the Elimination of All Forms of Discrimination against Women, state parties should recognize some groups of women as particularly vulnerable to sexual exploitation including Aboriginal women (Lynne, 2005). The fundamental issues that put Aboriginal girls in a disadvantageous situations today underline the importance of recognizing and addressing their sexual exploitation as integral to the dialogue on trafficking within Canada.

\section{Endnotes}

1. Throughout this document, the terms "First Nations", "Indigenous", "Aboriginal" and "Native" peoples have been used interchangeably. While these terms can include all peoples of Aboriginal ancestry, it is essential to note that First Nations are identified as a distinct group with unique legal status. Within Canada, Aboriginal peoples are constitutionally recognized as Inuit, Métis and First Nations.

2. The data for this study was generated as part of the author's work with Status of Women Canada in Ottawa. However, this paper expresses the views of the author and does not represent the official policy or opinion of Status of Women Canada or the Government of Canada.

3. Several factors explain the reluctance of girls to take action against their traffickers. Some of these include life threats to trafficked girls and their families, condition of confinement, fear of penalization, and lack of safe houses, shelters and other resources.

4. A trick pad is a place, usually a house in a secluded area, where girls are kept against their will and are coerced to engage in prostitution. Sometimes the girls are physically kidnapped and taken to trick pads (Urban Native Youth Association, 2002).

5. In many cases, the chemical dependency is a gradual transition beginning from alcohol, which is easily available, to marijuana, cocaine and then crystal meth.

6. For instance, Ma Mawi Wi Chi Itata Centre in Winnipeg, Manitoba, was instrumental in developing a safe house for sexually exploited Aboriginal girls in Winnipeg, aged 13-17, through the development of an advisory committee consisting of experiential victims of sexual exploitation who were consulted in planning the details of the site. The home called "Honouring the Spirit of Our Little Sisters" is for Aboriginal girls who have been sexually exploited. They are referred to this program from Child and Family Services and can stay as long as they want. The girls voluntary choose to be involved in the program and its location is kept hidden to protect its clients (Kotyk, 2003). 


\section{Bio}

Anupriya Sethi is a Canadian Commonwealth Scholar from India with two Masters degrees - a Masters in Social Work (MSW) from Carleton University in Ottawa and a Masters in Business Administration (MBA) from India. Her research interests include human trafficking, organ donation and organ trafficking, women's health, gender equality, and Aboriginal child welfare. Anupriya has authored reports on 'Trafficking of Women and Girls in Canada: A Health Perspective' and 'Demystifying the Urban Legend: The Reality of Organ Trafficking' and co-authored a report on 'Reconciliation: Looking Back, Reaching Forward, Indigenous Peoples and Child welfare'. She has also written articles on social policy and gender equality issues such as dowry harassment, domestic violence and family mediation. During her academic and professional career, Anupriya has won several scholarships, awards and distinctions including a Canadian Commonwealth Scholarship awarded by the Government of Canada, two full scholarships under Department for International Development Shared Scholarship Scheme from the Government of United Kingdom and a Government of India National Scholarship. Prior to coming to Canada, Anupriya has worked as a Family Counsellor in India. Anupriya is currently working as a Policy Analyst with the Labour Program of the Human Resources and Social Development Canada.

\section{References}

Amnesty International Canada. (2004). Canada: Stolen Sisters-AHumanRightsResponsetoDiscrimination and Violence Against Indigenous Women in Canada. Ottawa: Amnesty International.

AssistantDeputy Ministers'Committee on Prostitution and the Sexual Exploitation of Youth. (2001). Sexual Exploitation of Youth in British Columbia. Victoria: Ministry of Attorney General, Ministry for Children and Families, and Ministry of Health and Ministry Responsible for Seniors.

Bennett, M. \& Shangreaux, C. (2005). Applying Maslow's Hierarchy Theory. The First Peoples Child and Family Review, 2(1), 89-116.

Blackstock, C., Clarke, S., Cullen, J., D’Hondt, J., and Formsma, J. (2004). Chapter Eight: Sexual Exploitation. In Keeping the Promise The Convention on the Rights of the Child and the Lived Experiences of First Nations Children and Youth, pp. 182-196. Ottawa, ON: First Nations Child \& Family Caring Society of Canada. Retrieved on 10 August 2007 from http://www.fncaringsociety. ca/docs/KeepingThePromise.pdf.

Bowen, R. (2006). From the Curb: Sex Workers' Perspectives on Violence and Domestic Trafficking. Vancouver: British Columbia Coalition of Experiential Women.
Canadian Housing and Renewal Association with Novac, S., Serge, L., Eberle, M., \& Brown, J. (2002). On Her Own: Young Women and Homelessness in Canada. Ottawa: Status of Women Canada. Retrieved on 1 August 2007 from http://www. swc-cfc.gc.ca/pubs/pubspr/0662318986/200303 $\underline{0662318986 \text { e.pdf. }}$

Criminal Intelligence Service Canada (CSIC). (2004). 2004 Annual Report on Organized Crime in Canada. Ottawa: Criminal Intelligence Service Canada.

Downe, P with 'Ashley-Mika'. (2003). “The People We Think We Are": The Social Identities of Girls Involved in Prostitution. In K. Gorkoff \& J. Runner (Eds.), Being Heard. The Experiences of Young Women in Prostitution. Winnipeg, MB: Fernwood Publishing and RESOLVE (Research and Education for Solutions to Violence and Abuse).

Gorkoff, K. \& Runner, J. (2003). 'Introduction: Children and Youth Exploited Through Prostitution'. In K. Gorkoff \& J. Runner (Eds.), Being Heard. The Experiences of Young Women in Prostitution. Winnipeg, MB: Fernwood Publishing and RESOLVE (Research and Education for Solutions to Violence and Abuse)

Farley, M. \& Lynne, J. (2005). Prostitution of Indigenous Women: Sex Inequality and the Colonization of Canada's First Nations Women. Fourth World Journal, 6(1), 1-29.

Fontaine, N. (2005). Surviving Colonization: Anishinaabe Ikwe and Gang Participation. In Gillian Balfour and Elizabeth Comack (Eds.), Criminalizing Women: Gender and (In)justice in Neoliberal Times. Winnipeg, MB: Fernwood Publishing.

Hamilton, A. \& Sinclair, C. (1991). Report of the AboriginalJustice Enquiryof Manitoba. Winnipeg: Aboriginal Justice Enquiry of Manitoba.

Jacobs, B. (2002). Native Women's Association of Canada's Submission to the United Nations Special Rapporteur Investigating the Violations of Indigenous Human Rights. Ottawa: Native Women's Association of Canada.

Kean, T. H. (1991). "Not in My Backyard": Removing Barriers to Affordable Housing, Report to President Bush and Secretary Kemp. Advisory Commission on Regulatory Barriers to Affordable 
Housing. Washington: United States Department of Housing and Urban Development.

Kotyk, R. (13 November, 2003). A place to call home: New safe house for sexually exploited youth tries to empower its residents. The Manitoban. Retrieved on 10 August 2007 from http://themanitoban. com/2003-2004/1119/ne_03.html.

Lynne, J. (2005). Prostitution of First Nations Women in Canada. Retrieved on 12 March 2007 from http://sisyphe.org/article.php3?id_article=1803.

Lynne, J. (1998). Colonialism and the Sexual Exploitation of Canada's First Nations Women. Paper presented at the American Psychological Association 106th Annual Convention, San Francisco, California, August 17, 1998

Mann, M. M. (2005). Aboriginal Women: An Issues Backgrounder. Ottawa: Status of Women Canada.

McIvor, S. D. \& Nahanee, T. A. (1998). 'Aboriginal Women: Invisible Victims of Violence'. In Bonnycastle, K. \& Rigakos, G.S (Eds.), Unsettling Truths: Battered Women, Policy, Politics, and Contemporary Research in Canada, pp. 63-69. Vancouver, BC: Collective Press.

McKenzie, B. \& Morrissette, V. (2003). Social Work Practice with Canadians of Aboriginal Background: Guidelines for Respectful Social Work. Envision: The Manitoba Journal of Child Welfare, 2, 13-39.

Native Women's Association of Canada (NWAC). (2007a). Aboriginal Women and Gangs: An Issue Paper prepared for the National Aboriginal Women's Summit at Corner Brook, NL. Ottawa: Native Women's Association of Canada. Retrieved on 6 August 2007 from http://www.nwac-hq.org/ en/documents/nwac-gangs.pdf.

Native Women's Association of Canada (NWAC). (2007b). Repeal of Section 67: An Issue Paper prepared for the National Aboriginal Women's Summit at Corner Brook, NL. Ottawa: Native Women's Association of Canada. Retrieved on 6 August 2007 from http://www.nwac-hq.org/en/ documents/nwac-repeal-of-s67-jun1607.pdf.

Native Women's Association of Canada (NWAC). (2006). Native Women's Association of Canada's Report in Response to Canada's Fourth and Fifth Reports on the International Covenant on
Economic, Social and Cultural Rights covering the period of September 1999- December 2004. Ottawa: The Author.

Nimmo, M. (2001). The "Invisible" Gang Members: A Report on Female Gang Association in Winnipeg. Manitoba: Canadian Centre for Policy Alternatives.

Olsen, S. (2005). Just Ask Us: A Conversation with First Nations Teenage Moms. Winlaw, BC: Sononis Press.

Ontario Federation of Indian Friendship Centres (OFIFC). (2000). Urban Aboriginal Child Poverty: A Status Report on Aboriginal Children and their Families in Ontario. Toronto: OFIFC

Ontario Native Women's Association. (1989). Breaking Free: A Proposal for Change to Aboriginal Family Violence. Thunder Bay: Ontario Native Women's Association.

Oxman-Martinez, J., Hanley, J., \& Gomez, F. (2005). 'Canadian Policy on Human Trafficking: A Four Year Analysis'. International Migration, 43(4), 7-29.

Royal Commission on Aboriginal Peoples (RCAP). (1996). Report of the Royal Commission on Aboriginal Peoples. Ottawa: Minister of Supply and Services Canada.

Save the Children Canada. (2000). Sacred lives: Canadian Aboriginal children and youth speak out about sexual exploitation. National Aboriginal Consultation Project. Ottawa: The Author.

Stout, M. D. \& Kipling, G. D. (1998). Aboriginal Women in Canada: Strategic Research Directions for Policy Development. Ottawa: Status of Women Canada.. Retrieved on 18 March 2007 from http:// www.swc-cfc.gc.ca/pubs/pubspr/index_e.html.

Thrasher, P. (2005). 'Child Sexual Exploitation, Port Alberni, B.C.'. B.C: Port Alberni Women's Resources Society.

Turenne, P. (5 June, 2006). 'Drugs and Violence, the Common Thread'. Edmonton Sun.

United Nations Crime and Justice Information Network. (2000). United Nations Protocolto Prevent, Suppress, and Punish Trafficking in Persons, especially Women and Children, Supplementing the United Nations Convention Against Transnational Organized Crime. Retrieved on 30 March 2007 from http:// 
www.uncjin.org/Documents/Conventions/dcatoc/ final documents 2/convention \%20traff eng.pdf.

Urban Native Youth Association. (2002). Full Circle. Vancouver: Urban Native Youth Association.

West, J. (2005). 'Pimps and Drug Traffickers Target First Nations School Girls'. First Nations Drum, Summer 2005. Retrieved on 1 April 2007 from http://www.firstnationsdrum.com/Sum2005/ WomGirls.htm.

Wilson, D. (November 2004). 'The Lonely Road of Matty Wilson'. The United Church Observer Magazine. Retrieved on 7 August 2007 from http://www.ucobserver.org/archives/nov04 cvst. shtml. 